\title{
Neonatal Immunoglobulin Secretion and Lymphocyte Phenotype in Rat Small Intestine Lamina Propria
}

\author{
FRANCISCO J. PÉREZ-CANO, CRISTINA CASTELLOTE, SILVIA MARÍN-GALLÉN, \\ ÀNGELS FRANCH, AND MARGARIDA CASTELL
}

Department of Physiology, Faculty of Pharmacy, University of Barcelona, E-08028 Barcelona, Spain

\begin{abstract}
We characterized the lymphocyte phenotype and the ability to produce Ig by lamina propria (LP) cells from rat ileum throughout the suckling period. In the first week after birth, $<10 \%$ of LP lymphocytes were $\mathrm{B}$ cells, but at weaning, this figure rose to $>30 \%$ as found in the adult. These B cells did not bear surface $\operatorname{Ig} \mathrm{A}(\operatorname{sg} \mathrm{A}-)$. However, the number of $\operatorname{sIg} \mathrm{A}+$, which may correspond to B blast cells because they were outside lymphocyte cytometer gate, increased. In LP, IgM-secreting cells (SC) appeared during the second week of life, and IgA-SC were detected later but at a lower number. Regarding LP T cells, $\mathrm{CD} 8+$ cells were more abundant than CD4+ cells along the first 2 postnatal weeks, and CD $3+\mathrm{CD} 8 \alpha \alpha+\mathrm{TCR} \alpha \beta+\mathrm{CD} 5-\mathrm{CD} 25-$ was their predominating phenotype. In this 2 -wk period, between 8 and $20 \%$ of LP were natural killer cells. LP CD4+ lymphocytes in neonatal rats showed increasing co-expression of $\operatorname{TCR} \alpha \beta$, whereas the co-expression of $\mathrm{CD} 90$ decreased and the CD4 + CD25 + cell percentage did not achieve adult values. In
\end{abstract}

\section{ABSTRACT}

conclusion, in the first $2 \mathrm{wk}$ of the rat life, the gut LP immune system shows abundant CD8 $\alpha \alpha+$ cells, including NK cells. Thereafter, LP B cells increase dramatically and Ig-SC appear, with IgM-SC being more abundant than IgA-SC. CD4+ LP lymphocytes acquire a mature phenotype and adult proportions later after weaning. (Pediatr Res 58: 164-169, 2005)

$\quad$ Abbreviations
ELISPOT, solid-phase enzyme-linked immunospot
FBS, fetal bovine serum
GALT, gut-associated lymphoid tissue
LP, lamina propria
LPL, lamina propria lymphocytes
NK, natural killer
SIg, surface immunoglobulin
SC, secreting cells

The mucosal surface of the small intestine is constantly exposed to a large variety of foreign antigenic materials, such as dietary macromolecules, food proteins, and autochthonous microbiota, with the resulting antigenic stimulation (1). The intestinal mucosa contains gut-associated lymphoid tissue (GALT), the largest immunologic tissue in the body, which deals with these luminal antigens. Anatomically, GALT consists of organized lymphoid structures and diffuse populations of cells. Organized GALT comprises Peyer's patches, isolated follicles, and mesenteric lymph nodes. Diffuse GALT consists of two distinct populations above and below the basement membrane: the intraepithelial lymphocytes and lamina propria (LP) mononuclear cells, including lamina propria lymphocytes

Received May 20, 2004; accepted October 25, 2004.

Correspondence: Dr. Margarida Castell, Departament de Fisiologia, Facultat de Farmàcia, Av. Joan XXIII s/n, E-08028 Barcelona, Spain; Pe-mail: margaridacastell@ub.edu.

This study was supported by grants from the Ministerio de Ciencia y Tecnología (AGL 2000-0913) and from the Generalitat de Catalunya (2001SGR-000141). F.J.P.C. is a holder of a fellowship from the Generalitat de Catalunya (2000 00340 FI), and S.M.G. is a holder of a fellowship from the University of Barcelona.

DOI: 10.1203/01.PDR.0000156367.60769.36
(LPL). Both diffuse compartments contain mature effector $\mathrm{T}$ lymphocytes, and the LP compartment also contains Igproducing plasma cells (2). The intestinal immune response is primarily characterized by the production of secretory IgA by plasma cells, which predominate in human intestinal LP and represent $\sim 80 \%$ of all Ig-producing cells in the body $(3,4)$.

In humans, LP contains T CD4+ and T CD8+ lymphocytes in a similar proportion to peripheral blood, and $>95 \%$ of LP T cells express the antigenic receptor $\alpha \beta(2,5)$. LP CD $8+\mathrm{T}$ cells account for $30-40 \%$ of LP T cells, which include cytolytic effector cells (6). Both CD4+ and CD8+ LPL express CD25 to a similar extent, with total CD25 + cells amounting to $\sim 15 \%$ of human intestinal LPL (5). Moreover, human LP T cells are similar to memory cells in that they have low percentages of CD45RA + and high percentages of CD45RO+ and CD58+ cells (5). B cells in human LP are represented by a small population of scattered surface $\operatorname{IgA}+$ cells with specific markers of local memory cells and blasts $(3,4)$. In adult rats, the few data available on the phenotype of LPL are contradictory. LP B lymphocytes can amount to 8 or $28 \%$, and the percentage of $\mathrm{T}$ cells in LP oscillates between 31 and $65 \%$ (7,8). Moreover, 
the reports of the $\mathrm{CD} 4+/ \mathrm{CD} 8+$ ratio in rat $\mathrm{LP}$ are inconsistent $(7,8)$. A few NK cells and TCR $\gamma \gamma+$ lymphocytes are also found in LP (8).

Little information is available on GALT in the early stages of life. This system, which gradually matures during the postnatal period, is strongly influenced by antigenic stimulation. In early neonatal life, the intestine is challenged by both milk and microbial flora. Thereafter, as the diet changes from milk to solid food, microbial contents vary. This period seems essential for the complete maturation of the mucosal immune system. To contribute to the knowledge of diffuse GALT development, the main objective of this study was to characterize the phenotype of rat LPL and their ability to produce Ig in the ileum from birth until the end of suckling. The establishment of markers of LPL maturation by LPL phenotype and Ig-secretory pattern can shed some light on the development of oral tolerance and the physiologic activity to protect the neonate.

\section{METHODS}

Pregnant Lewis rats (G14) and 10-wk-old male Lewis rats (used as reference adults) were obtained from Harlan (Barcelona, Spain). Pregnant rats were housed in individual cages in controlled conditions of temperature and humidity in a 12:12-h light:dark cycle. They were monitored daily until delivery and allowed to deliver naturally. The day of birth was identified as day 1 of life. Litters were unified to eight pups per mother, with free access to the nipples and rat diet. Therefore, pups spontaneously started to combine breast milk with pellet food from days 15-17. Reference adult rats were housed four per cage and kept in the same conditions as pregnant rats. Adult rats were fed with commercial rat diet and water ad libitum. Studies were performed in accordance with the institutional guidelines for the care and use of laboratory animals established by the Ethical Committee for Animal Experimentation of the University of Barcelona, and procedures were approved by that committee.

Small intestine extraction. Rats were killed by humanitarian methods. The abdomen was opened, and the entire small intestine was flushed in situ with cold saline solution. Thereafter, it was removed and dissected from the mesentery. The intestine was divided into two halves, and for LPL isolation, only the distal small intestine (mainly ileum) was processed. The ileum samples from 1- to 4-d-old rats then were cut directly into 5 -mm pieces, whereas those from 5- to 14-d-old rats were opened lengthwise before cutting. From 15-d-old rats or adult rats, the intestine was everted, visible Peyer's patches were excised, and remaining tissue was cut.

Isolation of $\boldsymbol{L P L}$. LPL suspensions were prepared from tissues pooled from one to four rats, depending on their postnatal age. First, intraepithelial lymphocytes and epithelial cells were removed by subsequent incubations, at $37^{\circ} \mathrm{C}$ in a shaker, with DTT $(5 \mathrm{mM}, 1 \times 20 \mathrm{~min}$; Sigma Chemical Co., St. Louis, $\mathrm{MO}$ ) in HBSS without calcium and magnesium (BioWhittaker, Verviers, Belgium), EDTA ( 5 mM, $2 \times 30$ min; Panreac, Barcelona, Spain) in HBSS, and finally with RPMI $1640(1 \times 30 \mathrm{~min}$, BioWhittaker $)$. All culture media were supplemented with $5 \%$ fetal bovine serum (FBS; BioWhittaker). The remaining tissue then was minced and digested either by $300 \mathrm{U} / \mathrm{mL}$ collagenase (Type I; Sigma Chemical Co.; $90 \mathrm{~min}$ ) in the tissues used for LPL phenotypical characterization or by $1.5 \mathrm{mg} / \mathrm{mL}$ collagenase-dispase (Sigma Chemical Co.; $45 \mathrm{~min}$ ) in the tissues used for the solid-phase enzyme-linked immunospot (ELISPOT) assay. Both solutions were prepared in RPMI 1640 that contained $10 \% \mathrm{FBS}$, and incubations were performed in a shaker at $37^{\circ} \mathrm{C}$. Released cells were decanted from tissue pieces and centrifuged. Pellets were resuspended in RPMI 1640 with 5\% FBS and then subjected to LPL purification.

Purification of $\mathbf{L P L}$. The cell suspensions obtained by collagenase digestion were passed through a glass wool column $(0.145 \mathrm{~g}$; Merck, Darmstadt, Germany) placed in a $10-\mathrm{mL}$ syringe. The column then was washed twice with RPMI 1640 medium that contained 5\% FBS. The collected passing volume was centrifuged, and cells were resuspended in 44\% Percoll (Amersham Biosciences, Uppsala, Sweden). Each cell suspension was overlaid on $67.5 \%$ Percoll, and after centrifugation $(600 \times g, 30 \mathrm{~min}$, room temperature), viable lymphocytes were recovered from the interface. Cell number and viability were determined after staining with ethidium bromide (Sigma Chemical Co.) and acridine orange (Sigma Chemical Co.). For obtaining enough cells, sometimes LPL were pooled before staining. In the case of LPL by ELISPOT, the glass wool column purification was avoided to accelerate the culture and avoid unspecified cell stimulation of Ig-secreting cells (Ig-SC).

Immunofluorescence staining and flow-cytometer analysis. LPL $\left(2 \times 10^{5}\right)$ were stained by a double immunofluorescence technique. The mouse anti-rat $\mathrm{MAb}$ conjugated to FITC or phycoerythrin used here include anti-CD3 (1-F4), anti-CD4 (OX-35), anti-CD5 (OX-19), anti-CD8 $\alpha$ (OX-8), anti-CD25 (OX39 ), anti-CD45 (OX-1), anti-TCR $\alpha \beta$ (R73), anti-TCR $\gamma \gamma$ (V65), and antiNKR-P1A (10/78), all from BD Pharmingen (San Diego, CA); anti-CD2 (OX-34), anti-CD45RA (OX-33), and anti-CD90 (OX-7) from Caltag (Burlingame, CA); and anti-CD8 $\beta$ (3.41), anti- $\alpha$ Ig chain (MARA-1), and anti- $\kappa$ Ig chain (OX-12) from Serotec (Kidlington, Oxford, UK). Cells were incubated with a mixture of saturating concentrations of FITC- and phycoerythrinconjugated MAb in PBS that contained 2\% FBS and $0.1 \% \mathrm{NaN}_{3}$ (Merck) at $4^{\circ} \mathrm{C}$ in the dark for $20-30 \mathrm{~min}$. After washing, they were fixed with $0.5 \%$ p-formaldehyde (Merck) and stored at $4^{\circ} \mathrm{C}$ in the dark until analysis by flow cytometry. For each sample, a negative control staining using an isotypematched MAb was included. Analyses were performed with an Epics XL flow cytometer (Coulter Corp., Hialeah, FL). The scatter gate for LP cells was established on the basis of the cluster that showed TCR + and CD45RA + cells, i.e. that contained $\mathrm{T}$ and $\mathrm{B}$ lymphocytes, from adult rat samples, referred to as LPL gate or R1. A second gate, called R2, then was established to study cells with surface IgA expression ( $\operatorname{IgA}+$ ) that contains other types of B lineage cells. Results from CD45, CD4, CD8, NKR-P1A, CD45RA, sIg and sIgA stainings were expressed as the percentage of positive cells with respect to total gated lymphocytes (R1). Other cytometer data were expressed as the percentage of positive cells with respect to a particular LPL subset (CD4+, CD8+, or NKR-P1A+ cells)

ELISPOT assay. An ELISPOT technique was used to enumerate Ig-SC from the LP. ELISPOT assay was performed using a modification of a protocol described elsewhere (9). Ninety-six-well nitrocellulose plates (MultiScreen MAHAN 4510; Millipore, Eschborn, Germany) were coated with $100 \mathrm{~L} /$ well of anti-rat IgA, IgG, or IgM MAb (A93-2, G53-238, and G28-5 clones, respectively; BD Pharmingen) at $15 \mu \mathrm{g} / \mathrm{mL}$ in PBS (overnight at $4^{\circ} \mathrm{C}$ in humidified chamber). After washing, the remaining binding sites were blocked with $10 \%$ FBS in RPMI medium for $1 \mathrm{~h}$ at $37^{\circ} \mathrm{C}$. Thereafter, serial dilutions of LP cell suspensions $\left(2 \times 10^{5}, 1 \times 10^{5}, 5 \times 10^{4}\right.$, and $2.5 \times 10^{4}$ cells $)$ were incubated for $20 \mathrm{~h}$ at $37^{\circ} \mathrm{C}$. The plates then were washed to remove the cells with PBS that contained $0.25 \%$ Tween-20 (PBS-Tw, 10 washes) and with distilled $\mathrm{H}_{2} \mathrm{O}$ (one wash). Biotin-conjugated anti-rat $\operatorname{IgA}, \operatorname{IgG}$, or IgM MAb (2 $\mu \mathrm{g} / \mathrm{mL}$; BD Pharmingen) then was added to the corresponding wells and incubated for $2 \mathrm{~h}$ at room temperature. After washing $(5 \times$ PBS-Tw), 100 $\mu \mathrm{g} /$ well extravidin-peroxidase conjugate $(4 \mu \mathrm{g} / \mathrm{mL}$ in PBS; Sigma Chemical Co.) was added for $1 \mathrm{~h}$. Plates were washed again $(5 \times \mathrm{PBS})$, and the substrate solution (3-amino-ethylcarbazole; Sigma Chemical Co., in $0.1 \mathrm{M}$ acetate solution plus $\mathrm{H}_{2} \mathrm{O}_{2}$ ) was added. The enzyme reaction was visualized after 30 $\mathrm{min}$, and the reaction was stopped with tap water. Spots were enumerated automatically by ELISPOT reader system (AID Diagnostica, Strassberg, Germany) and expressed as the number of Ig-SC per $10^{6}$ cells.

Statistical analysis. Statistical analysis was performed by conventional ANOVA. For each dependent variable, we considered animal age as the independent variable. When age had a significant effect on the dependent variable, post hoc comparisons (LSD test) were performed. Differences between adult and 21-d-old animals were analyzed using the Mann-Whitney $U$ test. Significant differences were accepted at $p<0.05$.

\section{RESULTS}

CD45+ percentage in LPL. The lymphocyte content in LP was established by forward scatter/side scatter cytogram gating on TCR + and CD45RA + cells from adult rats (R1; Fig. $1 a)$. The CD45 molecule was present in $95 \%$ of gated cells in adult age (Fig. 1b). However, at birth, only $35 \%$ of gated cells were CD45+ (Fig. 1b). The proportion of CD45 + LPL increased during suckling $(p<0.001)$, especially in the first $2 \mathrm{wk}$ of life, and on day 14, CD45 was present in almost $90 \%$ of gated cells (Fig. 1b).

Time course of B cells and sIgA+ cells in LP. B cells were determined by the surface expression of CD45RA, $\kappa$ chain (total surface $\operatorname{Ig}$ or $\mathrm{sIg}$ ), and $\operatorname{IgA}$ (surface $\operatorname{Ig} \mathrm{A}$ or $\mathrm{sIg} \mathrm{A}$; Fig. 2). In LPL gate R1, the percentages of CD45RA+ cells (Fig. 2a) and sIg + cells (Fig. $2 b$ ) during suckling were age dependent $(p<0.001)$ and showed a parallel time course. In both cases, 
(a)

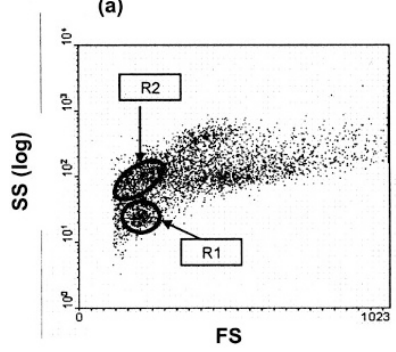

(b)

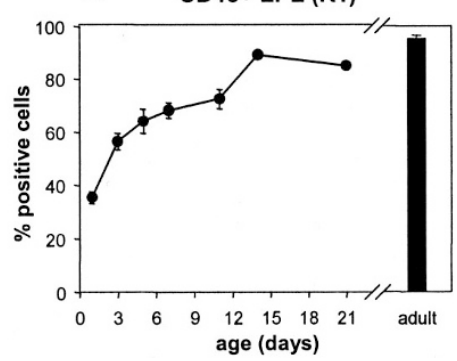

Figure 1. CD45 + cells in LPL gate during suckling period and in adult rats. (a) Representative LP cells dot-plot from an adult rat showing the cluster where T and B LPL are located (R1) and that with increased side scatter (R2), which includes sIgA + cells. (b) Time course of CD45+ cell percentage with respect to total LPL. Results are expressed as the mean \pm SEM of four to eight values, each one derived from one animal or pools of two to four animals depending on age.
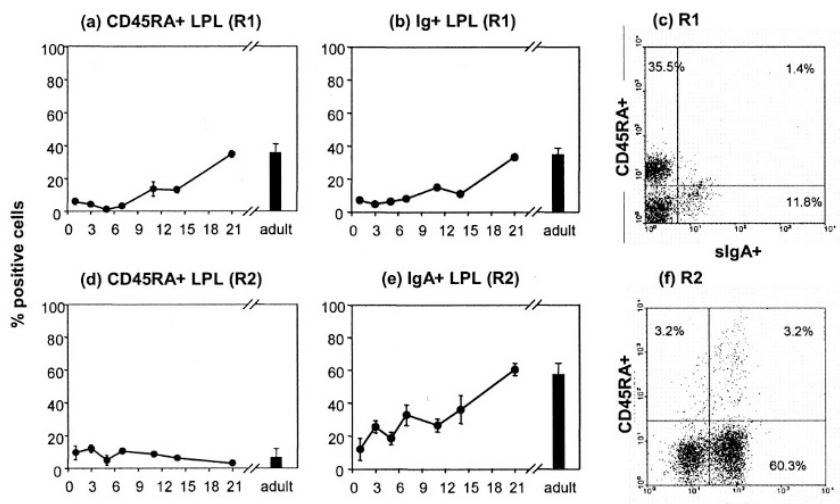

(e) $\lg \mathrm{A}+\mathrm{LPL}(\mathrm{R} 2)$

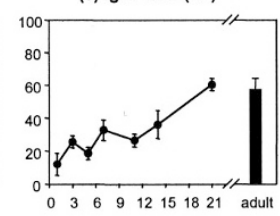

age (days)

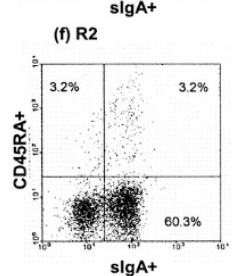

Figure 2. Differential flow-cytometer characteristics of LP B cell lineage. B cells in R1 gate showed as time course of the percentage of CD45RA+ $(a)$, time course of $\operatorname{sIg}+(b)$, and representative dot-plot showing $\operatorname{sIgA} / C D 45 \mathrm{RA}$ double staining in the ileum LP cells from a 21-d-old-rat (c). B blast cells in $\mathrm{R} 2$ gate shown as time course of the percentage of CD45RA $+(d)$, time course of $\operatorname{sIg}+(e)$, and representative dot-plot showing sIgA/CD45RA double staining in the ileum LP cells from a 21-d-old-rat $(f)$. In $a, b, d$, and $e$, positive cell percentages of total gated LPL results are expressed as the mean \pm SEM of four to eight values, each one derived from one animal or pools of two to four animals depending on age.

the percentage of B LPL did not exceed $15 \%$ of gated cells in the first $2 \mathrm{wk}$ of life but rose markedly in the third week of life, to reach adult percentages $(\sim 35 \%)$ on day 21 . The proportion of $\mathrm{B}$ cells co-expressing CD5 was $<1.5 \%$ throughout the period studied (data not shown).

Approximately $10 \%$ of cells in R1 (lymphocyte gate) were sIgA+ during suckling, decreasing to $<4 \%$ in adult $(p<0.05$ compared with day 21). CD45RA + B cells in R1 did not express $\operatorname{sIgA}$ (Fig. 2c). However, when we studied the expression of SIgA outside this gate, we found a cluster of positive cells that corresponded to cells with increased side scatter, defined as the R2 gate, which may correspond to B cell blasts or plasma cells, after which we defined the R2 gate (Fig. 1a). Inside this new defined gate (R2), the percentages of CD45RA + (Fig. 2d) and sIgA + cells (Fig. 2e) were established all along the suckling period and in adult rats. CD45RA + cell proportion in R2 gate oscillated between 3 and $12 \%$ throughout the studied period. However, $\operatorname{sIgA}+$ cell

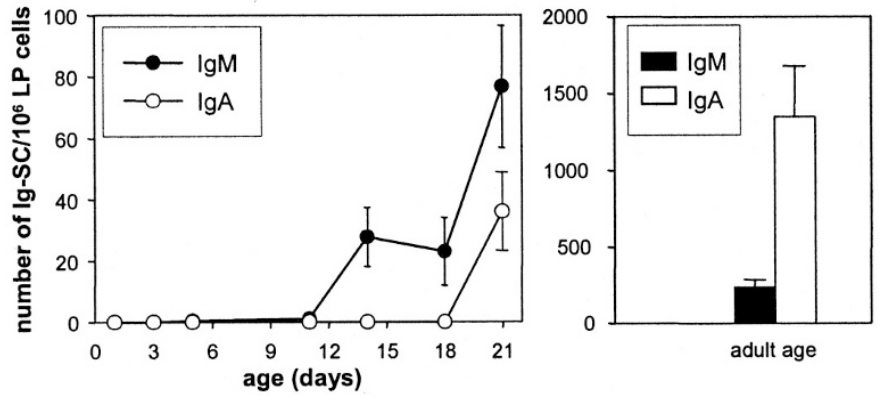

Figure 3. Time course of IgM- and IgA-secreting cells in ileum LP, as determined by the ELISPOT technique, during the suckling period $(a)$ and in adult rats $(b)$. Results are expressed as the mean \pm SEM of six values, each one derived from duplicates of four serial dilutions of cell suspensions.

percentage increased since birth, and on day 21, the proportion of sIgA + cells in R2 gate achieved adult values (60\%; Fig. $2 e$ ). Only a small percentage of these cells co-expressed CD45RA (Fig. 2f).

Time course of Ig-SC. Ig-SC in ileum LP from suckling and adult rats were counted by ELISPOT ( Fig. 3). IgM- and IgA-SC were not present in the first week of life; only a few cells acquired this ability for IgM during the second week, and at the end of the suckling period, the number of IgM- and IgA-SC increased dramatically ( $p<0.01$, day 21 versus days 14 and 18), IgM-SC being more abundant than IgA-SC $(p<0.01$ on day 18$)$. After weaning, this ratio switched, and IgA-SC became the main population in adult rats $(p<0.01, \operatorname{IgA}-\mathrm{SC}$ versus IgM-SC). In any case, the number of IgM- and IgA-SC was significantly higher in adults than in 21-d-old rats $(p<0.05)$. IgG-SC were not detected in rats during suckling (data not shown). Only $50 \%$ of adult rats (three of six) had IgG-SC but at levels close to the limit of detection (7.99 \pm 3.49 IgG-SC/10 $10^{6}$ cells; $\left.n=3\right)$.

Time course of CD4+ LPL subpopulations. The percentage of CD4+ cells in gate R1 (Fig. 4a) during suckling was age dependent $(p<0.001)$. The proportion of CD4+ LPL, which was predominant in the adult, was lower than $10 \%$ during the first $7 \mathrm{~d}$ of life and increased to $15 \%$ during the second and third weeks, which was still lower than that of adult animals $(60 \% ; p<0.01$; Fig. $4 a)$. Therefore, this expansion phase occurs long after weaning.

Most CD4+ LPL co-expressed the typical T lineage markers CD3 and other co-activation molecules such as CD2 and CD5 soon after birth (data not shown). TCR $\alpha \beta+$ cell percentage in CD4+ LPL was $60-70 \%$ on days $1-3$, achieved $>80 \%$ on day 5, and remained high throughout the suckling period (Fig. $4 b$ ).

The markers of early stages of development (CD90) and activation molecules (CD25) on CD4+ LPL showed an immature state during the suckling period compared with adult animals (Fig. $4 c$ and $d$ ). CD4+ LPL co-expressed CD90 in high percentages in the first days of life, but the levels decreased dramatically during the first week, to values ranging between 15 and $30 \%$. In adult rats, only $10 \%$ of CD4+ LPL were $\mathrm{CD} 90+(p<0.01$, compared with day 21). Moreover, throughout the suckling period, a small population of CD4+ LPL $(<24 \%)$ co-expressed the surface CD25 molecule. In contrast, CD25 was present in $>65 \%$ of CD4+ LPL from adult rats $(p<0.01$, compared with day 21$)$. 


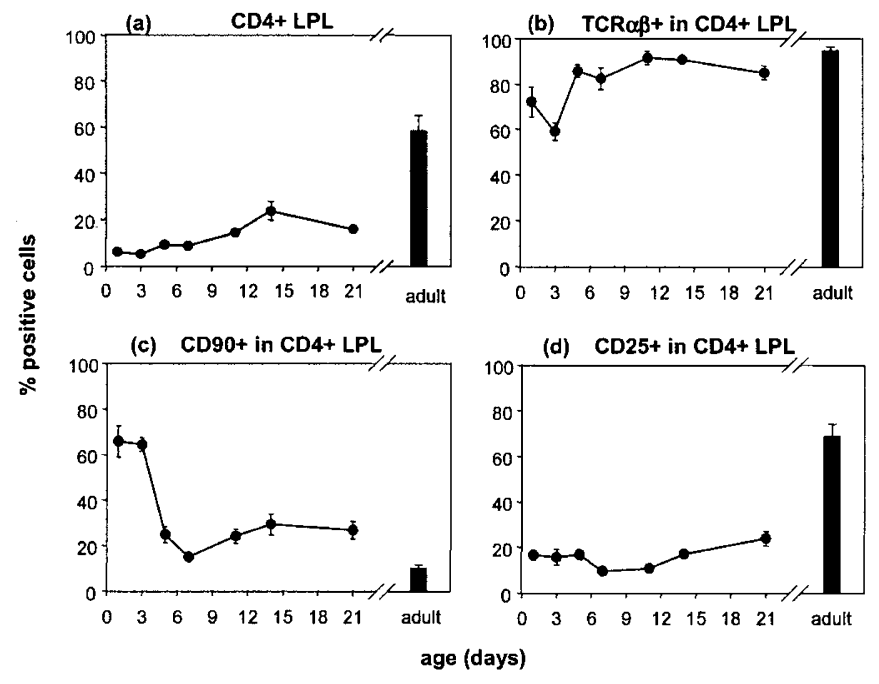

Figure 4. Time course of CD4+ LPL phenotypes during the suckling period and in adult rats. (a) LP CD4+ cell percentage of total gated lymphocytes. $\mathrm{TCR} \alpha \beta+(b), \mathrm{CD} 90+(c)$, and $\mathrm{CD} 25+(d)$ cells in LP CD4+ cells from ileum. Results are expressed as the mean \pm SEM of four to eight values, each one derived from one animal or pools of two to four animals depending on age.

Time course of CD8+ LPL subpopulations. The proportion of CD8+ cells in gate R1 (Fig. 5a) varied significantly during the suckling period $(p<0.0001)$. Surprisingly, with the exception of day $1, \mathrm{CD} 8+$ cells represented $\sim 40 \%$ of LPL during the first $2 \mathrm{wk}$ of life. Thereafter, the percentage decreased to $14 \%$ at weaning ( $p<0.0001$, day 21 versus day 14), and this value remained in adult animals. Thus, the CD8+ population was the most abundant during the first half of the suckling period but not in adults.

At birth, $>80 \%$ of CD8 + LPL co-expressed CD3 (data not shown). The time course of CD $8+$ LPL expressing TCR $\alpha \beta$ or $\mathrm{TCR} \gamma \delta$ was age dependent during suckling $(p<0.01)$, but in neither case was the adult proportion found at weaning (Fig. $5 b$ ). TCR $\alpha \beta$ was present in $\sim 40 \%$ of CD8 + LPL on day 1 and increased progressively thereafter but did not reach adult values on day $21(p<0.001)$. The percentage of CD8+LPL
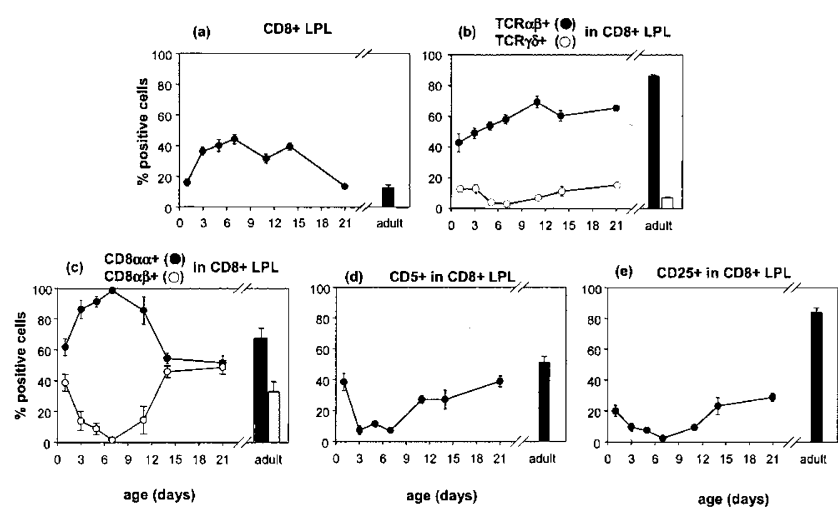

Figure 5. Time course of CD $8+$ LPL phenotypes during the suckling period and in adult rats. (a) LP CD8 + cell percentage of total gated lymphocytes. $\mathrm{TCR} \alpha \beta+$ and $\mathrm{TCR} \gamma \gamma+(b), \mathrm{CD} 8 \alpha \alpha+$ and $\operatorname{CD} 8 \alpha \beta+(c), \mathrm{CD} 5+(d)$, and $\mathrm{CD} 25+(e)$ cells in LP CD8 + cells from ileum. Results are expressed as the mean of four to eight values, each one derived from one animal or pools of two to four animals depending on age. bearing TCR $\gamma \delta$ fluctuated (2-12\%) during the first 2 wk of life. On day 21 , this proportion was significantly higher than that of adult rats $(p<0.001)$. Moreover, a small population of CD8-TCR $\gamma \delta+$ cells $(<1 \%$ of R1 gated LPL) was found throughout the suckling period and in the adult.

LPL include cells bearing CD 8 as the homodimer $\alpha \alpha$ or as the heterodimer $\alpha \beta$ (Fig. $5 c$ ). These phenotypes showed agedependent fluctuations $(p<0.0001)$ along the suckling period: almost all CD8 + LPL were CD8 $\alpha \alpha+$ until day 7, after which the percentage of $\operatorname{CD} 8 \alpha \beta+$ cells increased and reached 49 and $40 \%$ on day 21 and at adult age, respectively. Moreover, with the exception of day 1, most of CD8 + LPL did not bear CD5 during the first postnatal week (Fig. $5 d$ ). From day 11, the proportion of CD5 + in CD8 + LPL increased $(p<0.05$, day 11 versus day 7), and at weaning, it did not differ significantly from that of adult rats. Thus, the time course of both thymusderived markers, the $\mathrm{CD} 8+\mathrm{CD} 5+$ and $\mathrm{CD} 8 \alpha \beta+$ phenotypes, increased in parallel as expected.

Like CD4+ LPL, CD8 + were less activated during suckling than in the adult, as shown by the low proportion of cells expressing the IL-2R $\alpha$ chain (CD25) on their surfaces (Fig. $5 e$ ). In adult rats, $>80 \%$ of CD8 + LPL co-expressed CD25 $(p<0.01$, adult versus day 21).

Time course of LP natural killer cell subpopulations. Natural killer (NK) cell percentage in ileum LPL (Fig. 6a), as determined by NKR-P1A expression, fluctuated between 8 and $20 \%$ during the first $2 \mathrm{wk}$ of life (significant age effect, $p<$ 0.001 ). The NK population seemed to be important during this first stage of life, because this proportion was relatively higher than that in adult age (4\%). Apart from day 1, during the first 2 wk of life, $>50 \%$ of NKR-P1A+ LPL bore CD8 (Fig. 6b). During the last week of suckling, coinciding with the fall in the LP NK cell percentage, the proportion of CD8+ and CD8 - in NKR-P1A+ LPL switched, and most LP NK cells became CD8 - and remained so in adult life.

\section{DISCUSSION}

Here, we describe the phenotypic changes in LPL and the ability of LP cells to secrete Ig from neonatal rat ileum, throughout the suckling period, when rats spontaneously turn from a breast milk diet to solid food (10). The study was

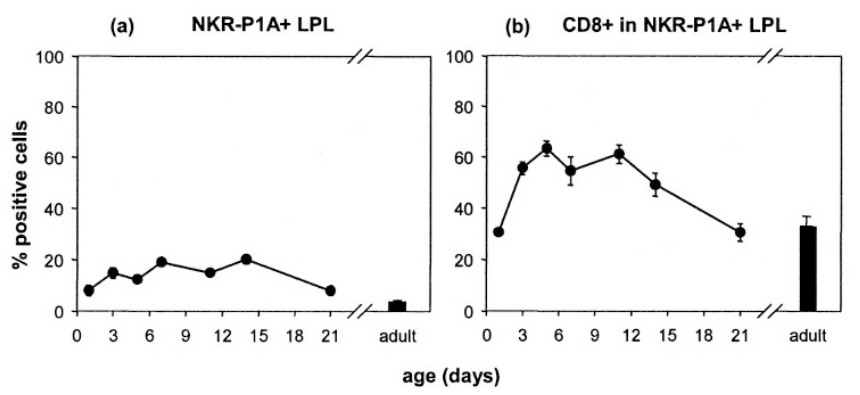

Figure 6. Time course of LP NK cells during the suckling period and in adult rats. (a) LP NKR-P1A+ cell percentage of total gated lymphocytes. (b) CD8+ cells in NKR-P1A+ LPL. Results are expressed as the mean of four to eight values, each one derived from one animal or pools of two to four animals depending on age. 
performed on the ileum, where indigenous microbes probably colonize the small intestine, thus activating GALT (11).

The intestinal immune system matures gradually after birth, influenced by antigenic stimulation. Although the intestinal LP is structurally well formed at birth, the gut is sterile and contains only a few lymphocytes. During early neonatal life, exposure to both milk proteins and the incipient microbial flora contributes to the maturation of the GALT (1). Intestinal microbial colonization follows a characteristic sequence depending on age and undergoes profound transitions when the animal begins to consume solid food (11). Thus, both lymphoid migration and expansion and diet and microbiota changes induce the complete development of the GALT lymphocyte subpopulations $(1,12)$.

Our results in adult rat LP show the predominance of CD4+ lymphocytes, followed by B cells, and only a small population of lymphocytes were CD8+. These results agree with other reports in humans and rats $(2,5,8)$. However, during the first $14 \mathrm{~d}$ of rat life, the proportion of CD8+ LPL was 2-4 times higher than that of CD4+ LPL. Moreover, in this period, there was no Ig-SC, and the B lineage was not well established until weaning.

Therefore, an age-dependent sequential predominance of lymphocyte subpopulations can be defined: CD8 + LPL, including NK cells, during the first $2 \mathrm{wk}, \mathrm{B}$ cells around weaning day, and CD4+ LPL in adult life. This developmental pattern may reflect the immune-physiologic requirements at each stage of life.

During the first weeks of life, the predominance of CD8+ T cells in intestinal LP suggests that this subset may be the first LPL dealing with the former pathogens and microbiota antigens. These first CD8 + LPL expressed the typical mucosal molecule CD $8 \alpha \alpha$ and lacked thymus-derived marker CD5. These data suggest that the subpopulation that controls the early antigen pressure of the luminal contents is thymus independent, developed in the intestine LP in a similar way to in the intraepithelial compartment (B). However, the rise in $\mathrm{CD} 8+\mathrm{CD} 5+$ cell percentage in LPL CD8+, parallel to the increase in $\operatorname{CD} 8 \alpha \beta+$ cells at the end of the second week of life, reflects a later increasing colonization and defense provided by CD $8+$ cell subsets originated from the conventional thymic selection process.

Another particular lymphocyte population that seems to be relevant during these first stages of development is the NK subset. The present study revealed a relatively high percentage of NK cells during the first $2 \mathrm{wk}$ of life; these cells were mostly CD8+, differing from adult age, when they did not bear CD8. In fact, in adult human and mouse LP, NK cells either have not been detected or have been found in very low numbers $(6,14,15)$. Although little is known about the presence and the phenotype of intestinal LP NK cells, this particular subset may act in the unspecific immune response needed on the first days of life, when subsets involved in adaptative immunity are not well developed.

During the first 2 wk of the rat life, when CD8 + T LPL and NK cells predominate, there are only a few $B$ cells in intestinal LP. However, at weaning, B cells became the main lymphoid population in this compartment. These B lymphocytes show the naive phenotype $(\mathrm{CD} 45 \mathrm{RA}+, \operatorname{sIg}+$, and $\operatorname{sIg} \mathrm{A}-)$. In par- allel to the increase in naive LP B cells, there was an expansion of $\operatorname{sIg} \mathrm{A}+$ cells with increased side scatter that may be B blasts cells, as described in humans (3). The number of both B lineage cells increased to reach the adult phenotype and proportion on day 21 . However, at weaning, the LP ability to secrete Ig was lower than in the adult, and IgM-SC were more abundant than IgA-SC. These results agree with those found during the first stages of human postnatal life, when intestinal IgM-SC are more abundant than $\operatorname{IgA-SC}(16,17)$, and with those found at $12 \mathrm{wk}$, when IgA-SC predominate in intestinal LP $(3,18-20)$. IgM can be secreted to the intestinal lumen, like IgA $(17,21)$. Thus, in LP at early stages of development, IgM-SC may be a key component of the mucosal barrier. Our results indicate that both the local expansion of total Ig-SC and the switch to $\operatorname{Ig} \mathrm{A}$ must be directed by postweaning-related challenges.

CD4+ LPL, the most predominant subset in adult rat LP, was the last lymphocyte population to acquire mature phenotype and proportion that occurs after weaning. Therefore, as the Ig-SC, postweaning-related challenges are probably essential for mature CD4+ LPL expansion. Differences from the adult phenotype were partially due to CD90 and CD25 expression. The immature phenotype of LP CD4 + T cells during suckling was confirmed by the higher presence of $\mathrm{CD} 90$, which are associated with early stages of maturation (22). CD25 was present only in a low percentage of LP CD4 + cells in suckling rats, but it was mainly expressed in the adult CD4+ LPL, which indicates that this activation state was acquired after weaning. These CD4+CD25+ cells in LP may be regulatory T cells (23) that inhibit the immune responses against microbiota and food antigens, preventing autoimmunity and inflammatory response. However, CD25 in LPL may also reflect a state of activation or differentiation distinct from that of activated peripheral blood lymphocytes: the latter normally progress through the cell cycle after activation, whereas intestinal LP $\mathrm{CD} 25+\mathrm{T}$ cell proliferation is rare (24). Moreover, intestinal LP T cells seem to have a low surface density of CD25 (25), indicating either that they have not undergone maximal stimulation or that they bore an advanced memory phenotype (26).

\section{CONCLUSION}

In summary, we have reported changes in phenotypical and functional characteristics of the small intestine immune system in neonatal rats, showing a sequential development and predominance of each subset during ontogeny. In particular, during the suckling period, the first stage was characterized by abundant thymus-independent CD $8 \alpha \alpha+\mathrm{CD} 5-\mathrm{LP}$ cells and NK CD8 + LP cells, which may provide unspecific immune defense in the developing GALT. Later in the suckling period, the proportions of B cells and Ig-SC increased, and the CD4+ mature cell phenotype was consolidated after weaning. Our results point to the rapid development of the LPL population during neonatal life in standard conditions of lactation and spontaneous solid food intake. The mechanisms by which nutrients, nonnutrients, and the intestinal scenario may affect the process of intestinal lymphocyte maturation require further investigation. 
Acknowledgments. We thank Ana M. Gonzalez-Castro for technical assistance and Laura Colell and Encarna Tovar for help in laboratory work. We also thank the "Serveis CientíficoTècnics" of the University of Barcelona, especially Dr. J. Comas, for expert assistance in flow cytometry and Dr. Jordi Vilaplana for advice in statistical analysis.

\section{REFERENCES}

1. Menezes JS, Mucida DS, Cara DC, Alvarez-Leite JI, Russo M, Vaz NM, de Faria AM 2003 Stimulation by food proteins plays a critical role in the maturation of the immune system. Int Immunol 15:447-455

2. Shanahan F 1994 The intestinal immune system. In: Johnson LR (ed) Physiology of the Gastrointestinal Tract. Raven Press, New York, pp 643-684

3. Farstad IN, Carlsen H, Morton HC, Brandtzaeg P 2000 Immunoglobulin A cell distribution in the human small intestine: phenotypic and functional characteristics. Immunology 101:354-363

4. Brandtzaeg P, Baekkevold ES, Morton HC 2001 From B to A the mucosal way. Nat Immunol 2:1093-1094

5. James SP, Kiyono H 1999 Gastrointestinal lamina propria T cells. In: Ogra PL, Mestecky J, Lamm ME, Strober W, Bienenstock J, McGhee JR (eds) Mucosal Immunology. Academic Press, San Diego, pp 381-396

6. Kelsall B, Strober W 1999 Gut-associated lymphoid tissue. Antigen handling and T lymphocyte responses. In: Ogra PL, Mestecky J, Lamm ME, Strober W, Bienenstock J, McGhee JR (eds) Mucosal Immunology. Academic Press, San Diego, pp 293-317

7. Lyscom N, Brueton MJ 1983 The development of intraepithelial and Peyer's patch lymphocytes sub-types in the small intestine of newborn rats. Clin Exp Immunol 54:158-162

8. Bruder MC, Spanhaak S, Bruijntjes JP, Michielsen CP, Vos JG, Kuper CF 1999 Intestinal $\mathrm{T}$ lymphocytes of different rat strains in immunotoxicity. Toxicol Pathol 27:171-179

9. Carol M, Lambrechts A, Van Gossum A, Libin M, Goldman M, Mascart-Lemone F 1998 Spontaneous secretion of interferon and interleukin $\gamma$ by human intraepithelial and lamina propria gut lymphocytes. Gut 42:643-649

10. Henning SJ, Guerin MD 1981 Role of diet in the determination of the jejunal sucrase activity in the weanling rat. Pediatr Res 15:1068-1072
11. Savage DC 1977 Microbial ecology of the gastrointestinal tract. Ann Rev Microbiol 31:107-133

12. Steege JC, Buurman WA, Forget PP 1997 The neonatal development of intraepithelial and lamina propria lymphocytes in the murine small intestine. Dev Immunol 5:121128

13. Lefrancois L, Puddington L 1995 Extrathymic intestinal T-cell development: virtual reality? Immunol Today 16:16-21

14. Abuzakouk M, Carton J, Feighery C, O'Donoghue DP, Weir DG, O'Farrelly C 1998 $\mathrm{CD} 4+\mathrm{CD} 8+$ and $\mathrm{CD} 8 \alpha+\beta-\mathrm{T}$ lymphocytes in human small intestinal lamina propria. Eur J Gastroenterol Hepatol 10:325-329

15. Tagliabue A, Befus AD, Clark DA, Bienenstock J 1982 Characteristics of natural killer cells in the murine intestinal epithelium and lamina propria. J Exp Med 155:1785-1796

16. Husband AJ, Gleeson M 1996 Ontogeny of mucosal immunity-environmental and behavioral influences. Brain Behav Immun 10:188-204

17. Perkkio M, Savilahti E 1980 Time of appearance of immunoglobulin-containing cells in the mucosa of the neonatal intestine. Pediatr Res 14:953-955

18. Brandtzaeg P, Nilssen DE, Rognum TO, Thrane PS 1991 Ontogeny of the mucosal immune system and IgA deficiency. Gastroenterol Clin North Am 20:397-439

19. Brandtzaeg P 1998 Development and basic mechanisms of human gut immunity. Nutr Rev 56:S5-S18

20. Allen WD, Porter P 1977 The relative frequencies and distribution of immunoglobulin bearing cells in the intestinal mucosa of neonatal and weaned pigs and their significance in the development of secretory immunity. Immunology 32:819-824

21. Cripps AW, Gleeson M 1999 Ontogeny of mucosal immunity and aging. In: Ogra PL, Mestecky J, Lamm ME, Strober W, Bienenstock J, McGhee JR (eds) Mucosal Immunology. Academic Press, San Diego, pp 253-266

22. Kroese FG 1998 Immunology of the rat. In: Pastoret PP, Griebel P, Bazin H, Govaerts A (eds) Handbook of Vertebrate Immunology. Academic Press, San Diego, pp 137-198

23. Annacker O, Pimenta-Araujo R, Burlen-Defranoux O, Bandeira A 2001 On the ontogeny and physiology of regulatory T cells. Immunol Rev 182:5-17

24. Zeitz M, Schieferdecker HL, Ullrich R, Jahn HU, James SP, Riecken EO 1991 Phenotype and function of lamina propria T lymphocytes. Immunol Res 10:199-206

25. Haverson K, Bailey M, Stokes CR 1999 T-cell populations in pig intestinal lamina propria: memory cells with unusual phenotypic characteristics. Immunology 96:66-73

26. Yang H, Parkhouse RM 1996 Phenotypic classification of porcine lymphocyte subpopulations in blood and lymphoid tissues. Immunology 89:76-83 